\title{
Acyclovir in the prevention of duodenal ulcer recurrence
}

S J Rune, J Linde, O Bonnevie, H Draminsky Petersen, F Bendtsen, J H Wandall, C Gluud, J Eriksen, H Skovbjerg, M Vilien, M Olesen, S Larsen, P Schlichting, M Gormsen, H R Wulff, $\mathrm{S}$ Vadstrup, B F Vestergaard

\begin{abstract}
This study tests the hypothesis that reactivation of a latent herpes simplex virus infection may be a cause of recurrent duodenal ulceration. Patients with recently healed duodenal ulcer were entered into a double blind, randomised study of maintenance treatment with the antiviral drug acyclovir (400 mg bid) versus placebo, to determine if suppression of herpes virus infection would influence the natural history of the ulcer disease. One hundred and fifteen patients entered the trial and 76 patients completed it according to the protocol. Endoscopy was performed when ulcer symptoms recurred and at the end of the 25 week trial period. In the acyclovir group the cumulated relapse rate was $63 \%$ compared with $56 \%$ in the placebo group (NS). This result suggests that reactivation of herpes simplex virus is not a cause of recurrent duodenal ulcer.
\end{abstract}

The rapidly changing epidemiology of duodenal ulcer during this century' points to an extrinsic factor as a possible cause of the disease, and 30 years ago it was proposed that infection with herpes simplex virus might be involved in the pathogenesis. ${ }^{2}$ Since then this hypothesis has been supported by demonstration of herpes simplex virus in human vagal ganglia ${ }^{3}$ and the finding of significantly higher titres of anti herpes simplex type 1 antibodies in patients with duodenal ulcer than in seropositive control individuals. ${ }^{4}$ Herpes simplex virus has also been found in the gastric mucosa, but only in patients being treated with immunosuppressive agents. ${ }^{5}$

As acyclovir was shown to be safe and effective in the prophylaxis against reactivation of herpes simplex virus ${ }^{6-9}$ we decided to use this drug to test the hypothesis that herpes virus is responsible for recurrent duodenal ulceration.

\section{Methods}

PATIENTS

The patients included in this study had an endoscopically diagnosed duodenal ulcer which subsequently had been treated with an $\mathrm{H}_{2}$ blocker. Patients were considered eligible for inclusion if their duodenal ulcer was seen to have healed within eight weeks of treatment, if they had become symptom free, if their $\mathrm{H}_{2}$ blocker treatment was stopped, and if they were found to be seropositive for antiherpes simplex antibodies.

Patients who gave their informed consent entered the double blind study. They were allocated at random to take trial tablets containing either acyclovir $400 \mathrm{mg}$ or placebo, one to be taken in the morning and one in the evening for 25 weeks. The patients were seen at five week intervals for clinical assessment and a tablet compliance count.

The patients contacted the clinic if ulcer symptoms recurred on three or more days within the same week, and an upper gastrointestinal endoscopy was then performed.

Treatment was stopped if duodenal ulcer recurrence was verified at endoscopy. Al patients who completed the 25 week study without symptomatic ulcer recurrence were endoscoped at the end of the study. Patients who missed taking tablets for more than three days during a five week period and patients who developed a gastric ulcer without a simultaneous duodenal ulcer were withdrawn.

The efficacy variable was endoscopic recurrence of a duodenal ulcer and the data were subjected to both a 'per protocol analysis' - that is, including only patients who completed the study according to the protocol, and an 'intention to treat' analysis - that is, including all patients who entered the study, and considering all patients who were withdrawn as treatment failures-namely, those having relapsed.

\section{Results}

One hundred and fifteen patients entered the study and the treatment groups were found to be comparable. Details are shown in Table I. Thirty nine patients were withdrawn from the study for the following reasons: 19 because of non-compliance - that is, missed drug intake on more than three days during a five week period; seven because endoscopy was not performed at symptomatic relapse before treatment with an $\mathrm{H}_{2}$

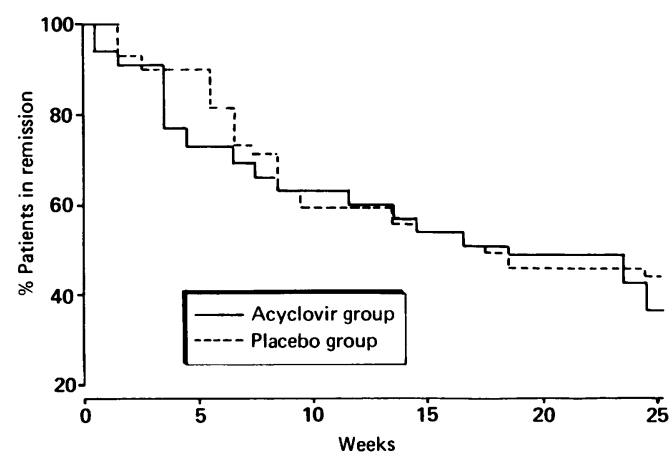

Figure: Endoscopically verified recurrence of a duodenal ulcer during 25 weeks of treatment with acyclovir or placebo. Data are based on 35 patients from the acyclovir group and 41 from the placebo group, who completed the study according to the protocol. 
TABLE I Patient characteristics

\begin{tabular}{llll}
\hline & $\begin{array}{l}\text { Acyclovir } \\
n=55\end{array}$ & $\begin{array}{l}\text { Placebo } \\
n=60\end{array}$ & \\
\hline Ratio Men:women & $37: 18$ & $36: 24$ & NS \\
Mean age (SD), years & $54 \cdot 4(11 \cdot 8)$ & $53 \cdot 5(14 \cdot 5)$ & NS \\
History of cold sore & 10 & 17 & NS \\
Cigarette smokers (n) & 35 & 37 & NS \\
\hline
\end{tabular}

NS=not significant, Student's non-paired $t$ test and Fischer's exact test.

TABLE II Cumulative recurrence rates for two analytical cohorts

\begin{tabular}{lll}
\hline & $\begin{array}{c}\text { Acyclovir } \\
n\end{array}$ & $\begin{array}{c}\text { Placebo } \\
n\end{array}$ \\
\hline 'Per protocol' cohort & $22 / 35(63 \%)$ & $23 / 41(56 \%)$ \\
'Intention to treat' cohort & $42 / 55(76 \%)$ & $42 / 60(70 \%)$ \\
\hline
\end{tabular}

blocker was given; five patients did not attend at scheduled visits; four patients developed a gastric ulcer and one patient an oesophageal ulcer; and three patients wanted to leave the study.

The cumulative recurrence rate of duodenal ulcer after 25 weeks was $63 \%$ in the acyclovir group and $56 \%$ in the placebo group (standard error of difference $=11 \cdot 0 \%$ ), Table II. The 'intention to treat' cohort showed a similar result with $76 \%$ and $70 \%$ relapses in the acyclovir and placebo group respectively. The time of recurrence did not differ between the two groups (Figure). Only one asymptomatic ulcer was found at endoscopy at 25 weeks. Fourteen patients (six acyclovir, eight placebo) developed symptomatic relapse with no demonstrable ulcer at endoscopy.

No side-effects were recorded.

\section{Discussion}

The aim of this clinical trial was to test the hypothesis that reactivation of a latent herpes simplex infection is a cause of recurrent duodenal ulceration. The results show that longterm treatment with acyclovir does not reduce the recurrence rate of duodenal ulcer, and this is a strong argument against the hypothesis, provided that the chosen regimen effectively prevents reactivation of herpes simplex virus. It has in fact been shown in several studies ${ }^{6-9}$ that the dose of acyclovir used in the present study reduces the risk of developing clinical or viro- logical recurrence of herpes simplex infection by at least $75 \%$. If acyclovir had prevented ulcer recurrence in, for example, 50 to $75 \%$ of the patients, the expected difference between the recurrence rates of the order of magnitude would be $30 \%$ to $50 \%$. That hypothesis, however, is not compatible with this study as the calculation of the $99 \%$ confidence limits of the observed difference shows that we are unlikely to have missed a difference larger than $22 \%$.

One of the arguments in favour of the hypothesis was that duodenal ulcer patients were found to have higher antiherpes virus antibody titres in their serum than matched controls. ${ }^{+}$The immune response to a chronic viral infection such as herpes is, however, regulated in a highly complex fashion involving many elements." Raised antibody titres to herpes simplex virus may therefore be explained by a non-specific hyper-responsiveness of ulcer patients and not necessarily by activation of the virus. This explanation is supported by the finding that ulcer patients also have higher titres of antibodies against rubella virus."

Acyclovir and placebo tablets were kindly provided by The Wellcome Research Labs, Beckenham, England.

1 Bonnevie 0 . Changing demographics of peptic ulcer disease. Dig Dis Sci 1985; 30 (suppl): 8S-14S

2 Knyvett AF. Peptic ulcer: Herpes simplex an aetiological agent? Med F A ust 1961; 22: 229-30.

3 Warren KG, Brown SM, Wroblewska 7 Gilden D, Koprowski H, Subak-Sharpe J. Isolation of latent Herpes simplex virus from the superior cervical and vagus ganglions of human beings. $N$ Engl f Med 1978; 298: 1068-9.

4 Vestergaard BF, Rune SJ. Type-specific Herpes simplex virus antibodies in patients with recurrent duodenal ulcer. Lancet 1980; i: $1273-5$

5 Howiler W, Goldberg HI. Gastroesophageal involvement in Herpes simplex. Gastroenterology 1976; 70:775-8.

6 Gluckman E, Lotsberg J, Devergie A, Zhao XM, Melo R, Gomez-Morales M, Mazeron MC, Perol Y. Oral acyclovir prophylactic treatment of herpes simplex infection after bone marrow transplantation. F Antimicr Chem 1983; 12 bone marrow trans

7 Wade J, Newton B, Flournoy N, Meyers JD. Oral acyclovir for prevention of herpes simplex virus reactivation after marrow transplantation. Ann Intern Med 1984; 100: 823-8.

8 Straus SE, Takiff $\mathrm{HE}$, Seidlin $M$, et al. Suppression of frequently recurring genital herpes. A placebo-controlled double-blind trial of oral acyclovir. N Engl f Med 1984; 310: 1545-50.

9 Douglas JM, Critchlow C, Benedetti J, et al. A double-blind study of oral acyclovir for suppression of recurrences of genital herpes simplex virus infection. $N$ Engl f Med 1984; 310: 1551-6.

10 Kohl S. Herpes simplex virus immunology: Problems, progress and promises. F Infect Dis 1985; 152: 435-40.

11 Van der Merwe CF, Alexander JJ. Herpes simplex virus and duodenal ulceration. Lancet 1982; i: 762 . 